\title{
Statistical Model for the Mechanical Properties of Al-Cu-Mg-Ag Alloys at High Temperatures
}

\author{
A. M. Al-Obaisi, ${ }^{1,2}$ E. A. El-Danaf, ${ }^{1}$ A. E. Ragab, ${ }^{3}$ M. S. Soliman, ${ }^{1}$ and A. N. Alhazaa ${ }^{4,5}$ \\ ${ }^{1}$ Mechanical Engineering Department, College of Engineering, King Saud University, P.O. Box 800, Riyadh 11421, Saudi Arabia \\ ${ }^{2}$ Mechanical Engineering Department, King Abdulaziz University, Jeddah, Saudi Arabia \\ ${ }^{3}$ Industrial Engineering Department, College of Engineering, King Saud University, P.O. Box 800, Riyadh 11421, Saudi Arabia \\ ${ }^{4}$ Physics \& Astronomy Department, Faculty of Science, King Saud University, P.O. Box 2455, Riyadh 11451, Saudi Arabia \\ ${ }^{5}$ King Abdullah Institute for Nanotechnology (KAIN), King Saud University, Riyadh, Saudi Arabia
}

Correspondence should be addressed to E. A. El-Danaf; edanaf@ksu.edu.sa

Received 2 March 2017; Revised 15 May 2017; Accepted 1 June 2017; Published 9 July 2017

Academic Editor: Markus Bambach

Copyright (c) 2017 A. M. Al-Obaisi et al. This is an open access article distributed under the Creative Commons Attribution License, which permits unrestricted use, distribution, and reproduction in any medium, provided the original work is properly cited.

Aluminum alloys for high-temperature applications have been the focus of many investigations lately. The main concern in such alloys is to maintain mechanical properties during operation at high temperatures. Grain coarsening and instability of precipitates could be the main reasons behind mechanical strength deterioration in these applications. Therefore, $\mathrm{Al}-\mathrm{Cu}-\mathrm{Mg}-\mathrm{Ag}$ alloys were proposed for such conditions due to the high stability of $\Omega$ precipitates. Four different compositions of $\mathrm{Al}-\mathrm{Cu}-\mathrm{Mg}-\mathrm{Ag}$ alloys, designed based on half-factorial design, were cast, homogenized, hot-rolled, and isothermally aged for different durations. The four alloys were tensile-tested at room temperature as well as at 190 and $250^{\circ} \mathrm{C}$ at a constant initial strain rate of $0.001 \mathrm{~s}^{-1}$, in two aging conditions, namely, underaged and peak-aged. The alloys demonstrated good mechanical properties at both aging times. However, underaged conditions displayed better thermal stability. Statistical models, based on fractional factorial design of experiments, were constructed to relate the experiments output (yield strength and ultimate tensile strength) with the studied process parameters, namely, tensile testing temperature, aging time, and copper, magnesium, and silver contents. It was shown that the copper content had a great effect on mechanical properties. Also, more than $80 \%$ of the variation of the high-temperature data was explained through the generated statistical models.

\section{Introduction}

For decades, the market of lightweight materials has been growing and enlarging year by year, due to the increasing demand for energy saving. Aluminum alloys are still one of the main lightweight materials under investigation. Development and design of high strength aluminum alloys to operate at elevated temperatures is getting great attention. Applications for high-temperature aluminum alloys include supersonic aviation and automotive components. However, stability of precipitates at high temperature is still a major concern. Strength at elevated temperature starts to deteriorate after a specific time because of precipitates coarsening. Thus, the objective of many researches, recently, is to develop and design new aluminum alloys with precipitates that are stable at high temperatures. The use of $\mathrm{Al}-\mathrm{Cu}-\mathrm{Mg}-\mathrm{Ag}$ aluminum alloys (AA2139 and AA2519) has increased substantially in aircraft and military applications due to their low density, exceptional toughness, and moderately high-temperature stability [1-3].

The Concorde was the most famous supersonic civil aircraft. It was adopted by French and British Airways. The Concorde alloy was $2618 \mathrm{~A}(\mathrm{Al}-2.2 \% \mathrm{Cu}-1.5 \% \mathrm{Mg}-1 \% \mathrm{Fe}-1 \% \mathrm{Ni}-$ $0.2 \% \mathrm{Si}$ ). The precipitates of $2618 \mathrm{~A}$ are stable at elevated temperature and this is the reason behind choosing this alloy; even so, the mechanical properties are not in the same level when compared with conventional aerospace aluminum alloys like 2024-T6 and 7075-T6 [4]. The temperature on the skin of the airplane body is about $127^{\circ} \mathrm{C}$, due to air friction at a speed of Mach 2.05 [5]. Despite its speed, the Concorde failed economically, because it can only carry up to 100 passengers and was not able to fly for a long distance. 
Therefore, $\mathrm{Al}-\mathrm{Cu}-\mathrm{Mg}-\mathrm{Ag}$ system was proposed to replace 2618A and other conventional aerospace aluminum alloys, 2024-T6 and 7075-T6, in view of the fact that these new alloys give high thermal stability and good mechanical properties $[5,6]$. Many recent publications $[1,7,8]$ have focused on investigating the evolution of microstructure and mechanical properties in these alloys.

A superior combination of high thermal stability and good mechanical properties comes from special precipitates called $\Omega$ [5]. Bakavos et al. [9] used transmission electron microscopy (TEM) to explore the habit planes of $\Omega$ precipitates. It was found that the habit planes of $\Omega$ with the matrix are $\{111\}_{\alpha}$. Regarding the morphology of $\Omega$ precipitates, Lumley and Polmear [10] stated that $\Omega$ has an orthorhombic plate-like shape. For the composition of $\Omega$ phase, researchers are still uncertain about it. Lumley and Polmear [10] mentioned that the composition of $\Omega$ was close to that of $\mathrm{Al}_{2} \mathrm{Cu}$ with $\mathrm{Mg}$ and $\mathrm{Ag}$ detected at $\alpha / \Omega$ interfaces. Gable et al. [11] studied the stability of $\Omega$ phase at different aging temperatures of 200 and $250^{\circ} \mathrm{C}$. It was shown that the density of $\Omega$ phase plates decreases intensely if the alloy is aged at a temperature at $250^{\circ} \mathrm{C}$ or higher for 30 minutes or longer. Also, Gable et al. [11] showed that the thickness of $\Omega$ phase increases significantly if the alloy is aged at $250^{\circ} \mathrm{C}$. Xiao et al. [12] confirmed this observation where the $\Omega$ phases are thermally stable at temperatures below $200^{\circ} \mathrm{C}$.

Bakavos et al. [9] investigated the precipitates of two alloys of $\mathrm{Al}-\mathrm{Cu}-\mathrm{Mg}$ with and without silver (Ag) addition. It was stated that the $\Omega$ phase was observed in both alloys. However, $\Omega$ phases in Al-Cu-Mg-Ag were finer compared with $\mathrm{Al}-\mathrm{Cu}-\mathrm{Mg}$ free of $\mathrm{Ag}$. Gable et al. [11] showed that the content of $\Omega$ phase is related to the content of $\mathrm{Mg}$. $\Omega$ phase works with the other well-known precipitates $\theta^{\prime}$ and $S$ to enhance the mechanical properties significantly. The habit planes of $\theta^{\prime}$ phases are $\{001\}_{\alpha}$ and have a composition of $\mathrm{Al}_{2} \mathrm{Cu}$ and tetragonal plate-like shape $[9,13]$. For $S$ phases, the habit planes are $\{001\}_{\alpha}$ and have a composition of $\mathrm{Al}_{2} \mathrm{CuMg}$ and a cubic shape [10]. The dominant phases in the Al$\mathrm{Cu}-\mathrm{Mg}-\mathrm{Ag}$ system which has a great effect on enhancing the mechanical properties are $\Omega$ and then $\theta^{\prime} . S$ has minor significance [10]. It has been shown [14] that the precipitation sequence is as follows:

$$
\text { GP zones } \longrightarrow \theta^{\prime \prime} \longrightarrow \theta^{\prime}+\Omega \longrightarrow \theta^{\prime}+S^{\prime} \longrightarrow S+\theta \text {. }
$$

Song et al. [15] studied the mechanical properties of three alloys, A2618 (Al-2.2\%Cu-1.5\%Mg-1\%Fe-1\%Ni-0.2\%Si), Al$8 \mathrm{Cu}-0.5 \mathrm{Mg}$ free of $\mathrm{Ag}$, and $\mathrm{Al}-8 \mathrm{Cu}-0.5 \mathrm{Mg}-0.6 \mathrm{Ag}$, at a wide range of temperatures from 20 to $300^{\circ} \mathrm{C}$. It was shown that the alloy with the addition of low content of $\mathrm{Ag}$ has better mechanical properties at low and high temperatures compared with other alloys. Xia et al. [16] investigated the effect of heat exposure on the mechanical properties of the aged alloy (Al-4.72Cu-0.45Mg-0.54Ag-0.17Zr). The aging process was conducted at a temperature of $165^{\circ} \mathrm{C}$ for $2 \mathrm{~h}$ (underaged condition). The heat exposure was implemented at $200^{\circ} \mathrm{C}$ for different times of exposure starting from zero to $100 \mathrm{~h}$. It was shown that there was an initial increase in strength with increasing duration of heat exposure, whereas after $10 \mathrm{~h}$ the strength started to decrease. The ultimate tensile stress (UTS) after $100 \mathrm{~h}$ of exposure was about $400 \mathrm{MPa}$, whereas it was $430 \mathrm{MPa}$ before exposure [16].

Liu et al. [17] studied the creep behavior of $\mathrm{Al}-5.33 \mathrm{Cu}$ $0.79 \mathrm{Mg}-0.48 \mathrm{Ag}-0.30 \mathrm{Mn}-0.14 \mathrm{Zr}$. The study on the three alloys was conducted at a temperature of $150^{\circ} \mathrm{C}$ as well as at stress of 150 to $300 \mathrm{MPa}$ for underaged conditions. It was shown that the steady creep rates were $0.12,0.06,0.03$, and $0.01 \%$ per hour at 150,200, 250, and $300 \mathrm{MPa}$, respectively [17]. Lumley et al. [18] explored the creep behavior of two alloys, that is, traditional aviation aluminum alloy ( $\mathrm{Al} \mathrm{2024)}$ and experimental alloy with composition of Al-5.6Cu- $0.45 \mathrm{Mg}$ $0.45 \mathrm{Ag}-0.3 \mathrm{Mn}-0.18 \mathrm{Zr}$ for two different aging conditions of underaged and fully hardened (T6) conditions. The creep test parameters were temperature of $300^{\circ} \mathrm{C}$ and stress of $150 \mathrm{MPa}$. It was obvious that the underaged condition gave a lower creep rate for both alloys. Al 2024 displayed secondary creep after $200 \mathrm{~h}$ and $400 \mathrm{~h}$ for T6 and underaged conditions, respectively, while the experimental alloy with low content of $\mathrm{Ag}$ did not show a secondary creep behavior for both aging conditions. Based on this result, Lumley and Polmear [10] investigated the creep behavior of underaged conditions for the previous experimental alloy that contained a low amount of Ag extensively at different creep circumstances. The creep test condition was a temperature of $130^{\circ} \mathrm{C}$ and stress of $200 \mathrm{MPa}$ for $20000 \mathrm{~h}$. It was represented that the creep rate percentage was about 0.4 and there was no secondary creep observed along the duration of the test [10].

Al-Obaisi et al. [19] studied the aging characteristic of eight different compositions of $\mathrm{Al}-\mathrm{Cu}-\mathrm{Mg}$ - $\mathrm{Ag}$ based on fullfactorial design at three different aging temperatures of 160 , 190 , and $220^{\circ} \mathrm{C}$ for a wide range of aging durations. Statistical modeling was constructed between hardness values and process inputs comprising aging temperatures and times, as well as weight percentages of alloying elements through Minitab software. It was presented that changing of weight percentages of alloying elements changed the hardness values significantly. Also, it was deduced that aging at $190^{\circ} \mathrm{C}$ gave good hardness values with reasonable aging duration that could be appealing to industry needs [19]. This temperature was used as an aging temperature for the current study.

Most researchers focused on studying the mechanical properties of a single composition of $\mathrm{Al}-\mathrm{Cu}-\mathrm{Mg}-\mathrm{Ag}$ and mostly at one aging condition. A complete study of mechanical properties at high temperatures for different aging conditions and different compositions of $\mathrm{Al}-\mathrm{Cu}-\mathrm{Mg}-\mathrm{Ag}$ is still required. This is the stimulation for the current work. Based on the fractional factorial design of the experiment, four alloys were prepared. They were tensile-tested at room temperature, $190^{\circ} \mathrm{C}$, and $250^{\circ} \mathrm{C}$ and at two different aging conditions (underaged and peak-aged). Thus, the mechanical properties of the four alloys were related to the process parameters (tensile testing temperature, aging time, and alloying elements percentage) through statistical modeling. 
TABLE 1: Chemical compositions of the used alloys.

\begin{tabular}{lcccc}
\hline Alloy number & wt.\% Cu & wt.\% Mg & wt.\% Ag & wt.\% Al \\
\hline 1 & $5.0(+)$ & $0.5(-)$ & $0.3(-)$ & $0.3(-)$ \\
2 & $3.0(-)$ & $1.0(+)$ & $0.6(+)$ & Balance \\
3 & $3.0(-)$ & $0.5(-)$ & $0.6(+)$ & Balance \\
4 & $5.0(+)$ & $1.0(+)$ & Balance \\
\hline
\end{tabular}

TABLE 2: Chemical analysis of the investigated alloys (wt.\%)*

\begin{tabular}{lccccc}
\hline Alloy number & $\mathrm{Cu}$ & $\mathrm{Mg}$ & $\mathrm{Ag}$ & $\mathrm{Al}$ & $\mathrm{Cu} / \mathrm{Mg} \mathrm{ratio}$ \\
\hline 1 & 5.29 & 0.46 & 0.30 & Balance & \\
2 & 3.24 & 0.95 & 0.31 & Balance & 3.4 \\
3 & 3.15 & 0.47 & 0.62 & Balance & 6.8 \\
4 & 5.11 & 0.96 & 0.61 & Balance & 5.32 \\
\hline
\end{tabular}

${ }^{*}$ The rest of the alloying elements had the percentages $\mathrm{Si} \leq 0.05, \mathrm{Fe} \leq 0.2, \mathrm{Ni} \leq 0.03, \mathrm{Cr} \leq 0.056, \mathrm{Zn} \leq 0.031, \mathrm{Ti} \leq 0.016$, and $\mathrm{Mn} \leq 0.006$.

TABLE 3: Aging time for each aging condition.

\begin{tabular}{lcccc}
\hline Alloy number & \multicolumn{2}{c}{ Underaged } & \multicolumn{2}{c}{ Peak-aged } \\
& Aging time & Hardness (HV) & Aging time & Hardness (HV) \\
\hline 1 & $30 \mathrm{~min}$ & 124 & $2 \mathrm{~h}$ & 167 \\
2 & $30 \mathrm{~min}$ & 103 & $2 \mathrm{~h}$ & 132 \\
3 & $30 \mathrm{~min}$ & 97 & $8 \mathrm{~h}$ & 127 \\
4 & $10 \mathrm{~min}$ & 165 & $1 \mathrm{~h}$ & 172 \\
\hline
\end{tabular}

\section{Methodology}

2.1. Materials Preparation. Three alloying elements, namely, $\mathrm{Cu}, \mathrm{Mg}$, and $\mathrm{Ag}$, were added to $\mathrm{Al}$, with two levels for each, $(-)$ and $(+)$, based on fractional factorial design. Since it is a fractional factorial design, four alloys with compositions presented in Table 1 were cast in a steel mold. If a full factorial was employed, eight alloys would have been required [19]. The dimensions of the cast ingots were $100 \times 40 \times 15 \mathrm{~mm}$. The homogenizing process was conducted at $540^{\circ} \mathrm{C}$ for $24 \mathrm{~h}$. The four alloys were elementally analyzed through arc and spark excitation and the chemical analysis is displayed in Table 2. Then, the four alloys were hot-rolled at $450^{\circ} \mathrm{C}$. During the rolling process, $80 \%$ of the total thickness was reduced.

Tensile samples were wire-cut from the rolled alloys such that the tensile axis was parallel to the rolling direction. The tensile samples had a gage length of $10 \mathrm{~mm}$ and a crosssectional area of $4 \times 1.5 \mathrm{~mm}^{2}$. Solution treatment was carried out at a temperature of $540^{\circ} \mathrm{C}$ for Alloys 1 and 4 that have a higher content of $\mathrm{Cu}(5 \mathrm{wt} . \%)$ and at $500^{\circ} \mathrm{C}$ for Alloys 2 and 3 that have a low content of $\mathrm{Cu}(3 \mathrm{wt} . \%)$ to make sure that all four alloys were taken to a single phase region. Then, the four alloys were water-quenched. The aging process was implemented in a salt bath constituted of $50 \%$ potassium nitrate $\left(\mathrm{KNO}_{3}\right)$ and sodium nitrite $\left(\mathrm{NaNO}_{2}\right)$ at a temperature of $190^{\circ} \mathrm{C}$ with different aging times, and then the samples were water-quenched. The corresponding hardness values and aging times are displayed in Table 3. Tensile testing was performed for each sample at room temperature, $190^{\circ} \mathrm{C}$, and $250^{\circ} \mathrm{C}$ for each aging condition. The tensile test was carried out on an Instron machine model 3388 equipped with a data monitoring system. The testing temperature is controlled to be within $\pm 2^{\circ} \mathrm{C}$. The tensile data is processed using an Excel sheet and corrected for machine compliance.

The microstructure study was performed using SEM model JEOL 6610 LV and TEM JEOL model JEM-2100F-HR, operated at $200 \mathrm{kV}$. Thin foil, $\sim 300 \mathrm{~nm}$ thickness, for TEM investigation was prepared using focused ion beam system (JEOL JEM9320 FIB).

2.2. Design of Experiments (DOE). Fractional factorial is a well-known technique to be used in material and manufacturing experimentation. Several researchers made use of the technique in the process of investigating the significant factors in experiments [20-22]. A fractional factorial design reduces significantly the number of runs required, particularly in screening experiments where many factors are studied in order to decide the relative importance amongst them. The price of this reduction in the number of runs is the sacrifice of some higher order interactions.

In this research, a $2^{k-1}$ fractional factorial design was used with five factors, two levels each. The number of runs needed is 16 runs compared to 32 runs in a full-factorial $\left(2^{k}\right)$ design. The factors and levels evaluated in the research are listed in Table 4. Four numerical factors are used, namely, testing temperature and $\mathrm{Cu}, \mathrm{Mg}$, and $\mathrm{Ag}$ wt.\%. The fifth factor (aging time) was treated as a categorical parameter rather than numerical since the aging time for each alloy was different. Its levels are given as $\mathrm{U}(-1)$ and $\mathrm{P}(+1)$. It is worth noting that the model was built to study, solely, the hightemperature mechanical properties. 
TABLE 4: Factors and their levels in the experiment fractional factorial design for the high-temperature study.

\begin{tabular}{lccc}
\hline Factors & Index & Low $(-1)$ & Levels \\
\hline Aging time & & Underaged (U) & High $(+1)$ \\
Testing temperature $\left({ }^{\circ} \mathrm{C}\right)$ & $A$ & 190 & 250 \\
$\mathrm{Cu}($ wt.\%) & $B$ & 3.0 & 5.0 \\
$\mathrm{Mg}($ wt.\%) & $C$ & 0.5 & 1.0 \\
Ag (wt.\%) & $D$ & 0.3 & 0.6 \\
\hline
\end{tabular}

TABLE 5: Mechanical properties at room and high temperatures for each aging condition of all four alloys.

\begin{tabular}{|c|c|c|c|c|c|}
\hline \multirow[t]{2}{*}{ Alloy number } & \multirow[t]{2}{*}{ Testing temp. $\left({ }^{\circ} \mathrm{C}\right)$} & \multicolumn{2}{|c|}{ Yield strength (MPa) } & \multicolumn{2}{|c|}{$\begin{array}{l}\text { Ultimate tensile strength } \\
\text { (UTS) }(\mathrm{MPa})\end{array}$} \\
\hline & & Underaged & Peak-aged & Underaged & Peak-aged \\
\hline \multirow{3}{*}{1} & $20^{\circ} \mathrm{C}$ & 305 & 420 & 412 & 480 \\
\hline & $190^{\circ} \mathrm{C}$ & 315 & 350 & 354 & 372 \\
\hline & $250^{\circ} \mathrm{C}$ & 250 & 247 & 260 & 247 \\
\hline \multirow{3}{*}{2} & $20^{\circ} \mathrm{C}$ & 260 & 275 & 366 & 385 \\
\hline & $190^{\circ} \mathrm{C}$ & 250 & 210 & 310 & 237 \\
\hline & $250^{\circ} \mathrm{C}$ & 200 & 190 & 214 & 195 \\
\hline \multirow{3}{*}{3} & $20^{\circ} \mathrm{C}$ & 265 & 310 & 352 & 359 \\
\hline & $190^{\circ} \mathrm{C}$ & 190 & 250 & 220 & 271 \\
\hline & $250^{\circ} \mathrm{C}$ & 190 & 185 & 201 & 195 \\
\hline \multirow{3}{*}{4} & $20^{\circ} \mathrm{C}$ & 300 & 400 & 405 & 447 \\
\hline & $190^{\circ} \mathrm{C}$ & 295 & 320 & 320 & 341 \\
\hline & $250^{\circ} \mathrm{C}$ & 200 & 210 & 220 & 245 \\
\hline
\end{tabular}

\section{Results and Discussion}

3.1. Mechanical Properties. Figures 1(a)-1(c) represent examples of the engineering stress-strain curves for Alloy 4 tested at room temperature (a), $190^{\circ} \mathrm{C}(\mathrm{b})$, and $250^{\circ} \mathrm{C}$ (c), respectively, for the underaged and peak-aged conditions at $190^{\circ} \mathrm{C}$.

Table 5 summarizes the yield strength (YS) and ultimate tensile strength (UTS) values for each aging condition of all four alloys at room and high temperatures. As expected, the stress values decrease with temperature. For ultimate tensile strength (UTS) values, Alloy 1 gave the highest values for both underaged and peak-aged conditions. However, Alloy 3 gave the lowest values. The difference between Alloy 1 and Alloy 3 was around $120 \mathrm{MPa}$ at room temperature and about $50 \mathrm{MPa}$ at high temperature for peak-aged conditions, while for underaged conditions the difference was about $60 \mathrm{MPa}$ at both room and high temperatures. For yield strength (YS) values, Alloy 1 gave the highest values while Alloy 2 gave the lowest values at room temperature, but Alloy 3 exhibited the lowest values at high temperature. The difference between Alloy 1 and Alloy 2 was around 145 and $45 \mathrm{MPa}$ at room temperature for peak-aged and underaged conditions, respectively. For high temperature, the difference between Alloys 1 and 3 was about $60 \mathrm{MPa}$ for both aging conditions. Mostly, the stress values of peak-aged conditions were higher than of underaged conditions except at a temperature of $250^{\circ} \mathrm{C}$ at which underaged conditions were higher, while in
Alloy 2 the underaged condition is more superior compared to the peak-aged condition at both 190 and $250^{\circ} \mathrm{C}$. In Alloy 4 , stress values of the peak-aged condition were higher than of the underaged condition at all testing temperatures.

Figures 2-5 show the sensitivity of mechanical properties (UTS and YS) with temperatures of both underaged and peak-aged conditions of all four alloys. The data was linearly fitted and the negative slope was taken as an indicator of the thermal stability, in a sense that smaller negative slope can be interpreted as higher thermal stability. The negative slopes of yield strength for underaged conditions were between -0.17 and -0.37 . Alloys 3 and 4 had the highest negative slopes, while Alloys 1 and 2 had the lowest negative slopes. However, the negative slopes of ultimate tensile strength (UTS) for underaged conditions were between -0.59 and -0.74 . Alloys 3 and 4 had the highest negative slopes, while Alloys 1 and 2 had the lowest negative slopes.

The sensitivity of mechanical properties with temperatures of the peak-aged condition for all four alloys is as follows. For yield strength, the negative slopes were between -0.37 and -0.75 . Alloys 1 and 4 had the highest negative slopes, while Alloys 2 and 3 had the lowest negative slopes. However, the negative slopes of ultimate tensile strength (UTS) were between -0.67 and -0.93 . Alloys 1,2 , and 4 had higher negative slopes, while Alloy 3 had a lower negative slope. It is obvious that the sensitivity of peak-aged conditions is larger than of the underaged condition, which indicates that 


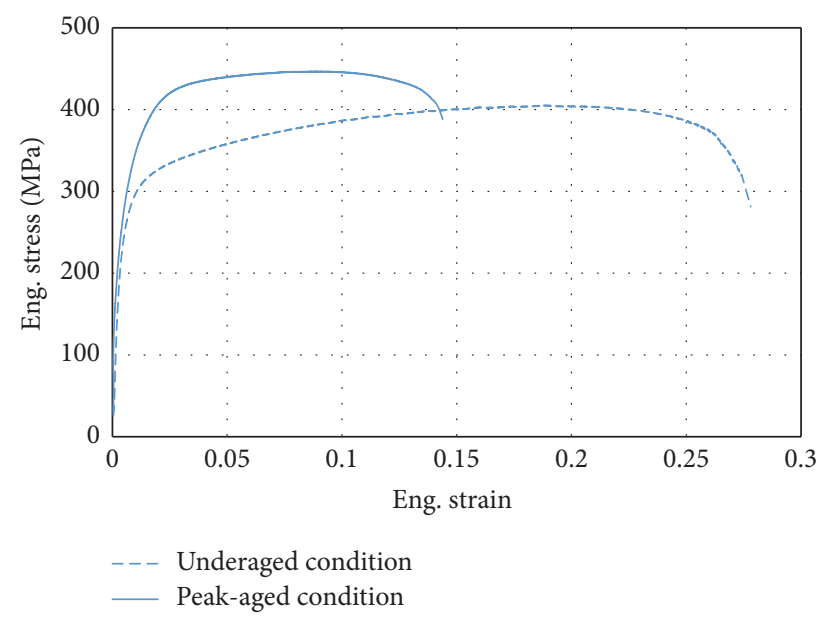

(a)

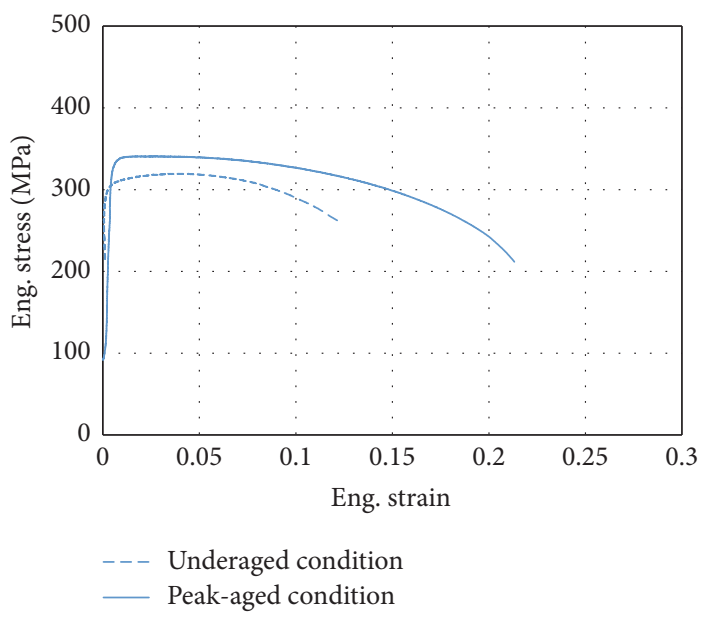

(b)

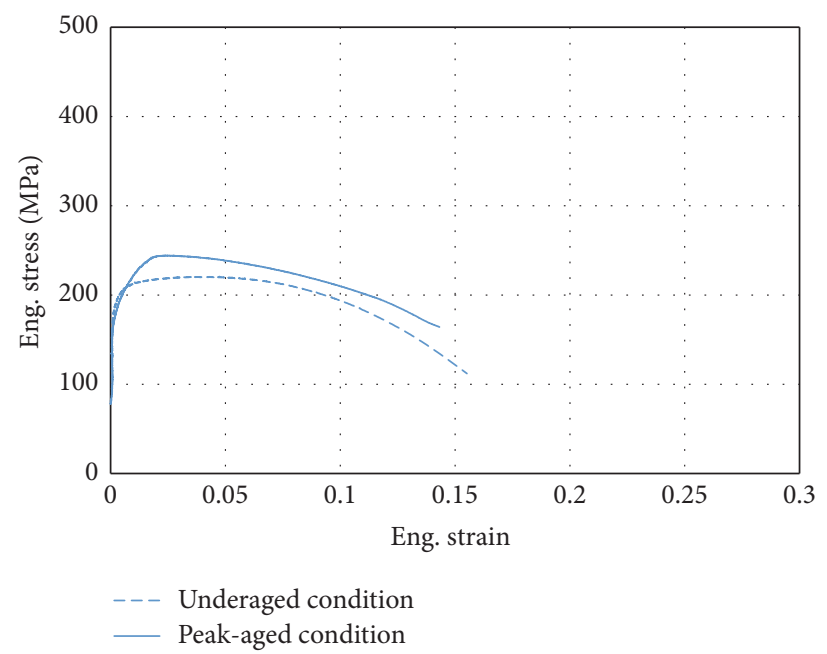

(c)

Figure 1: (a) Eng. stress-strain curves of Alloy 4 tested at room temperature for both aging conditions. (b) Eng. stress-strain curves of Alloy 4 tested at $190^{\circ} \mathrm{C}$ for both aging conditions. (c) Eng. stress-strain curves of Alloy 4 tested at $250^{\circ} \mathrm{C}$ for both aging conditions.

the underaged condition exhibits higher thermal stability. These observations are consistent with the results of Bai et al. [13].

It would be beneficial to estimate the behavior of the Al$\mathrm{Cu}-\mathrm{Mg}-\mathrm{Ag}$ system by comparing it with the Concorde alloy (A2618). The following data is extracted from [10]. It was shown that the yield strength values at $20,150,200$, and $250^{\circ} \mathrm{C}$ were $372,303,179$, and $62 \mathrm{MPa}$, respectively. For ultimate tensile strength, the values were $441,345,221$, and $90 \mathrm{MPa}$. The negative slope of the relation between yield strength and temperatures is -1.3 , while for ultimate tensile strength it is -1.46 . Therefore, Alloys 1 and 4 of peak-aged conditions, from the current study, gave better mechanical properties and lower sensitivity to temperatures. Also, it will be of interest to compare the present results with the behavior of $\mathrm{Al} \mathrm{7075,}$ which is one of the high strength aerospace aluminum alloys, at high temperatures. Polmear and Couper [23] showed that the yield strength of this alloy at room temperature is about $500 \mathrm{MPa}$, while at 190 and $250^{\circ} \mathrm{C}$ the yield strength is 200 and
$50 \mathrm{MPa}$, respectively. Thus, the performance of this alloy is catastrophic at high temperatures.

The superior thermal stability for some of the current alloys is attributed to a special new phase named $\Omega$ that forms as thin platelet precipitates on $\{111\}_{\alpha}$ planes ( $\alpha$ is an Al-based solid solution) and has either a hexagonal or an orthorhombic shape [24-26]. Since $\{111\}_{\alpha}$ are slip planes in $\alpha$ Al-based solid solution alloys, precipitation of $\Omega$ in these alloys tends to improve resistance to dislocation slip and improve mechanical properties [27].

3.2. Microstructure. A TEM study was conducted on Alloy 4 in the peak-aged condition as presented in Figure 6. Figure 6(a) represents a STEM dark field image of the alloy which shows the precipitated phases in bright color exhibiting different morphologies (rod and spherical shaped). The size of the precipitates ranged from 200 to $300 \mathrm{~nm}$. Figure 6(b) presents an EDS spectrum taken at one of these particles, showing the elemental composition in wt.\% to be $\mathrm{Al} 94.2, \mathrm{Cu}$ 


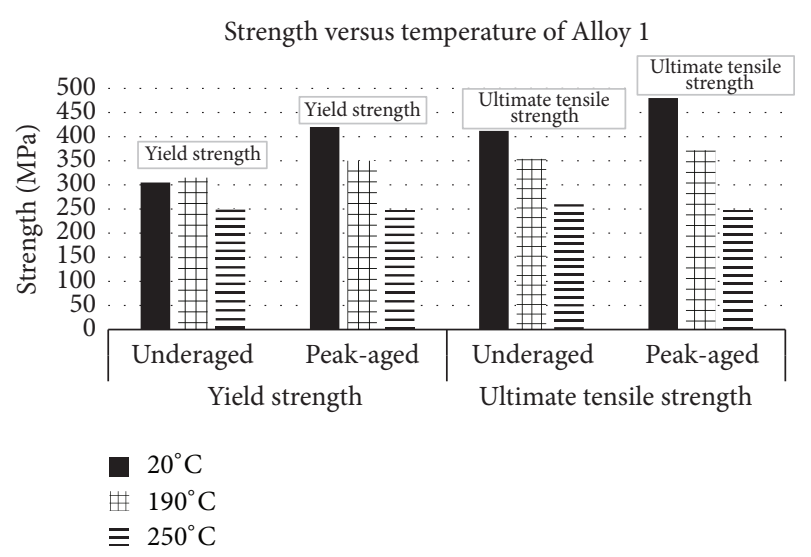

FIGURE 2: Yield strength (YS) and ultimate tensile strength (UTS) at various temperatures for both aging conditions of Alloy 1 .

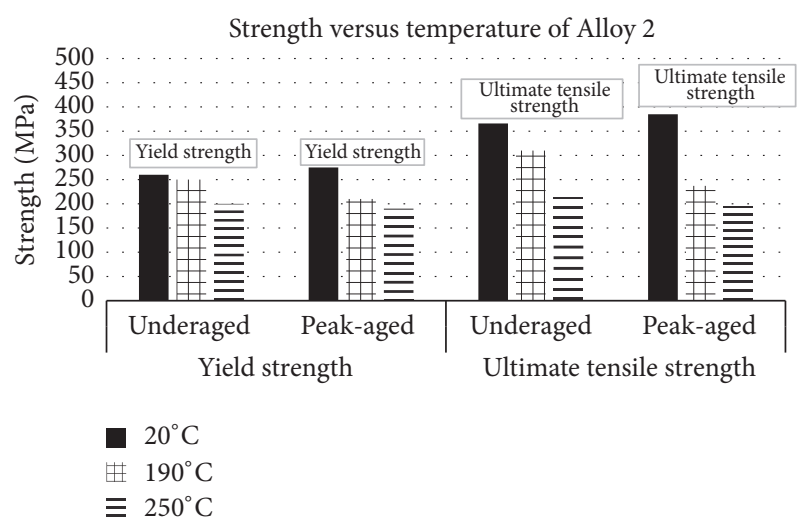

FIGURE 3: Yield strength (YS) and ultimate tensile strength (UTS) at various temperatures for both aging conditions of Alloy 2 .

4.3, and $\mathrm{Ag} 1.5 \mathrm{wt} . \%$. The amount of $\mathrm{Mg}$ was not detectable as it could be traces. This particle could be an $\Omega$ phase, according to the definition previously mentioned.

A detailed fractography investigation was carried out for Alloy 2, since its mechanical properties were more thermally stable for the two aging conditions. Figure 7 shows SEM images of the fractured surfaces of Alloy 2 tested at room temperature, $190^{\circ} \mathrm{C}$, and $250^{\circ} \mathrm{C}$, respectively, for different aging conditions. The images of the underaged conditions for all testing temperatures show that the dominant fracture mode is transgranular fracture regarding the observed dimples along the fracture surfaces. These dimples become shallow at higher testing temperatures. For peak-aged conditions, the fractured surfaces show a combined fracture mode including transgranular and intergranular fracture modes. This observation is consistent with the deduction that the underaged conditions are more thermally stable compared with peak-aged conditions. Some of the particles distributed on the fractured surfaces were chemically analyzed through energy dispersion spectroscopy (EDS) technique. Figure 8 shows the EDS spectrum of one of the particles distributed on the fractured surface of Alloy 2 tested at room temperature for the peak-aged condition. The particle size is about $1 \mu \mathrm{m}$.
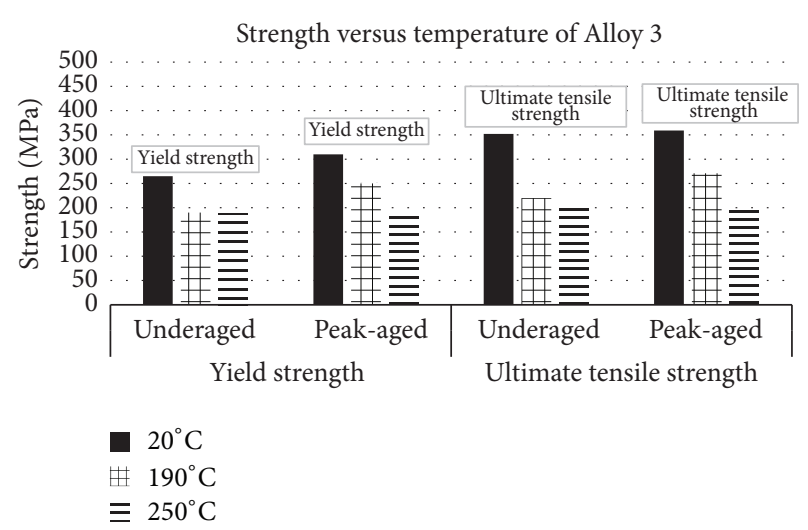

FIGURE 4: Yield strength (YS) and ultimate tensile strength (UTS) versus temperature for both aging conditions of Alloy 3 .

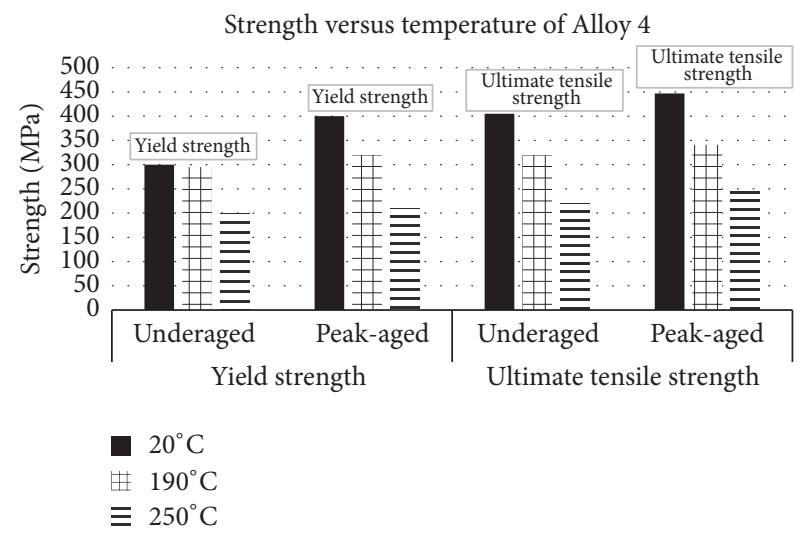

FIGURE 5: Yield strength (YS) and ultimate tensile strength (UTS) versus temperature for both aging conditions of Alloy 4.

The EDS spectrum displays clustering of $\mathrm{Cu}$ and $\mathrm{Al}$ atoms and to a much lesser extent the $\mathrm{Mg}$ and $\mathrm{Ag}$ atoms which could imply a coarsened phase of $\Omega$ precipitates. Figure 9 presents the EDS spectrum of one of the particles distributed on the fractured surface of Alloy 2 tested at $250^{\circ} \mathrm{C}$ for the peak-aged condition. The particle size is about $1 \mu \mathrm{m}$. The EDS spectrum exhibits clustering of $\mathrm{Cu}, \mathrm{Mg}$, and $\mathrm{Al}$ atoms which suggests a coarsened phase of $S$ precipitates.

3.3. Statistical Analysis. To prepare the fractional factorial design matrix, a full-factorial design was built for the basic factors $(A, B, C$, and $D)$ and a generator $(E=C D)$ was used to define the levels of the remaining factor $(E)$ in the matrix. Generators are, mainly, interactions of the basic factors that determine how a subset of experiments is selected from full set runs. The alias structure, given in Table 6, illustrates the confounding between factors and interactions due to the reduction in total runs in a fractional factorial design.

The set of experiments with measured responses is illustrated in Table 7. Responses yield strength and ultimate tensile strength are indexed as $Y$ and $U$, respectively. Since the design did not include replicates, the third-, fourth-, and fifth-level interactions were removed to free some 


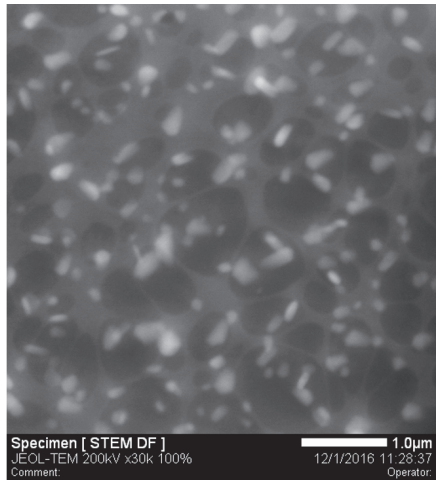

(a)
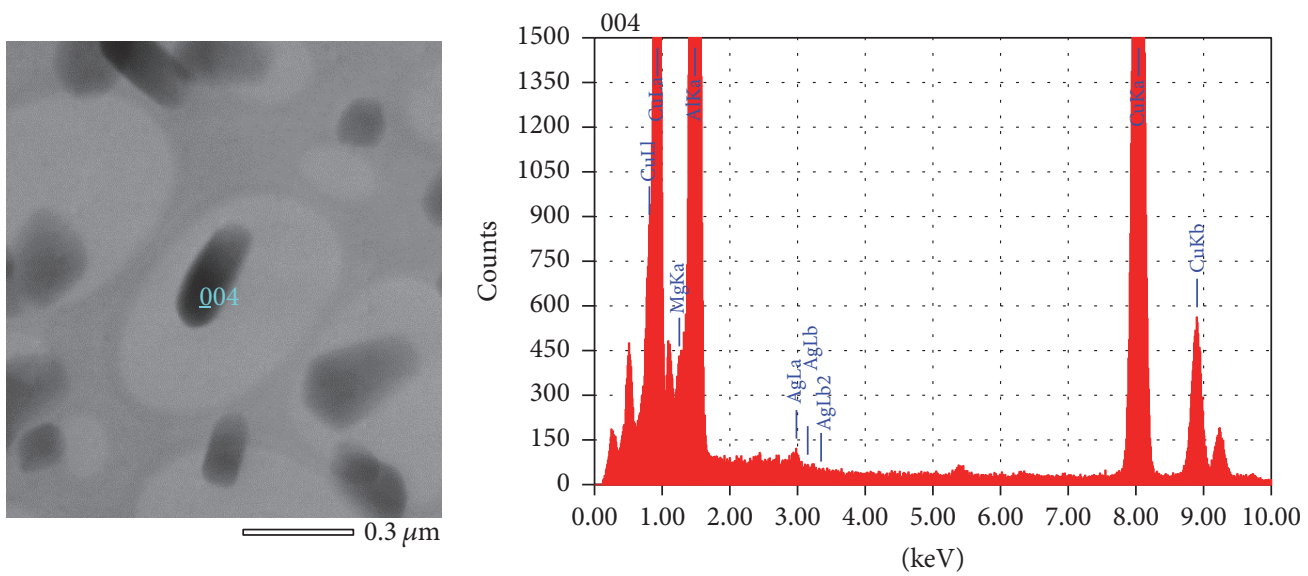

(b)

FIGURE 6: (a) STEM dark field image for Alloy 4 in the peak-aged condition. (b) EDS spectrum for the elemental composition of one selected precipitate.

TABLE 6: Alias structure for the high-temperature study.

\begin{tabular}{lc}
\hline Contrast & Estimates \\
\hline 1 & $A+A C D E$ \\
2 & $B+B C D E$ \\
3 & $C+D E$ \\
4 & $D+C E$ \\
5 & $E+C D$ \\
6 & $A B$ \\
7 & $A C+A D E$ \\
8 & $A D+A C E$ \\
9 & $A E+A C D$ \\
10 & $B C+B D E$ \\
11 & $B D+B C E$ \\
12 & $B E+B C D$ \\
13 & $A B C+A B D E$ \\
14 & $A B D+A B C E$ \\
15 & $A B E+A B C D$ \\
\hline
\end{tabular}

degrees of freedom for error estimation in order to test the significance of the effects of more important factors and second-order interactions. Analysis of variance was used to estimate the significance of each factor and interaction. Regression analysis was conducted to correlate each response to its significant parameters.

Analysis of variance (ANOVA) was used to decide which model terms (representing the studied process parameters and their interactions) affect significantly the experimental outputs. In ANOVA, the role of each term in the variability of experimental outputs is calculated as its adjusted sum of squares (Adj. SS). The value of Adj. SS of each term with respect to the total Adj. SS represents the contribution of this term to the total variability. Adj. MS for each term represents an estimate of population variance and is calculated by dividing its Adj. SS by its degrees of freedom. The F-value is then calculated for each term by dividing its Adj. MS by the error Adj. MS. A higher F-value indicates that the data contradicts more the test null hypothesis (which assumes nonsignificance of the considered term.) Another item to be calculated is the $P$ value. A lower $P$ value corresponds to a higher $F$-value. $P$ value less than the test confidence level (generally taken as 0.05 ) indicates significance of the considered term. 


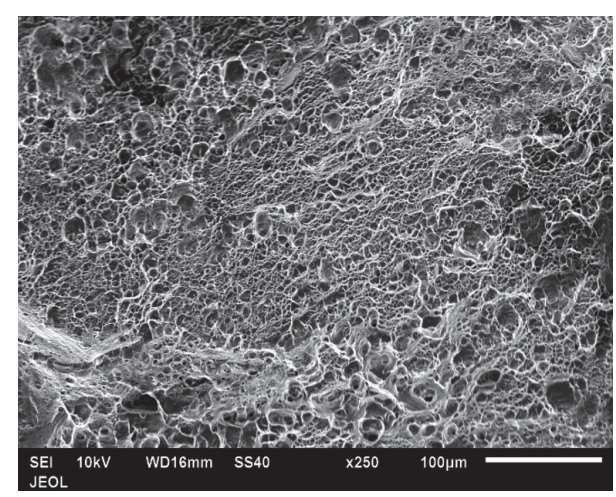

(a)

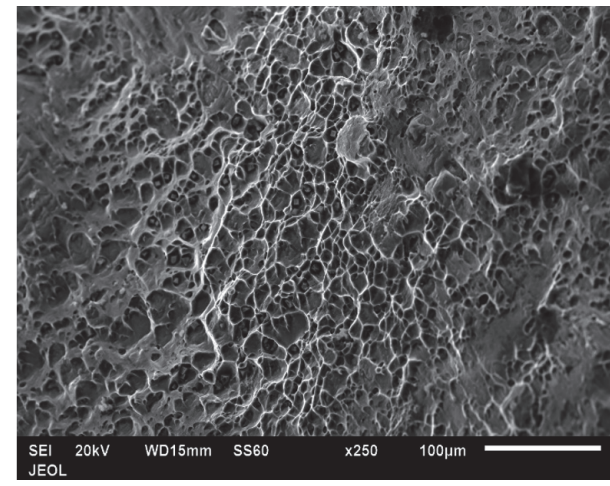

(c)

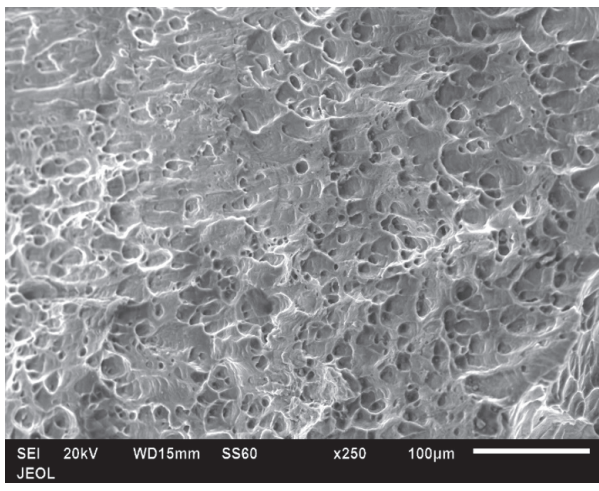

(e)

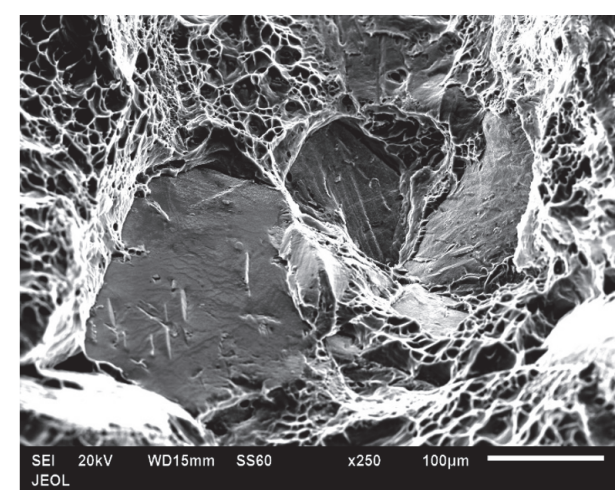

(b)

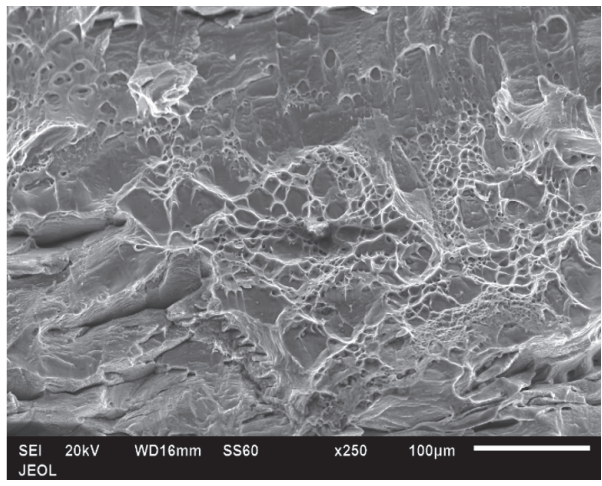

(d)

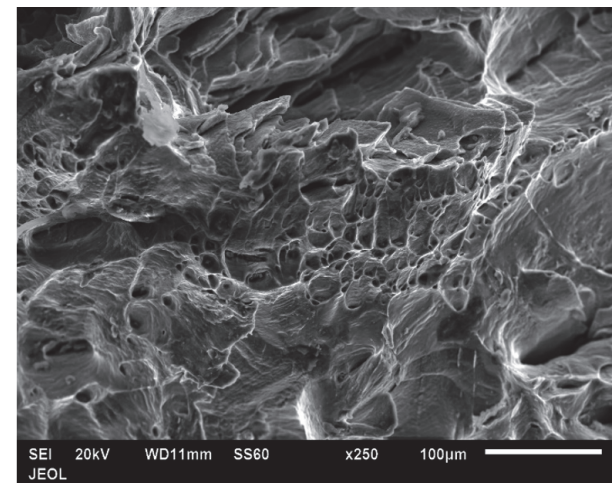

(f)

FIGURE 7: SEM images of the fractured surfaces of Alloy 2 produced by tensile testing: (a) underaged condition tested at room temperature, (b) peak-aged condition tested at room temperature, (c) underaged condition tested at $190^{\circ} \mathrm{C}$, (d) peak-aged condition tested at $190^{\circ} \mathrm{C}$, (e) underaged condition tested at $250^{\circ} \mathrm{C}$, and (f) peak-aged condition tested at $250^{\circ} \mathrm{C}$.

The ANOVA results for yield strength are given in Table 8. Model terms with $P$ value $>0.05$ are not significant and hence were removed from the model unless they are a part of a higher order interaction or their removal has a significant negative effect on the coefficient of determination ( $R$-squared). The model has an $F$-value of 23.7 with a $P$ value of about 0.000 implying that the model is significant relative to noise. Significant terms are $B$ (temperature), $C$ (copper content), and the interaction $B C$. Recall that the effect of $C$ includes the interaction $D E(\mathrm{Mg}$ and $\mathrm{Ag}$ ) as given by the alias structure. Assuming that the third- and fourthlevel interactions are negligible, the effects of factor $B$ and interaction $B C$ are calculated with no interference from other terms. The results suggest that aging time and magnesium content do not affect the alloy yield strength. The values of the adjusted sum of squares (Adj. SS) show that the variability in the measured yield strength comes mainly from the copper content and testing temperature.

The model analysis summary is illustrated in Table 9. The adjusted $R$-squared equal to 0.86 implies that the model represents $86 \%$ of the variation in the data. The predicted $R$-squared was calculated as 0.78 , within an acceptable difference from the adjusted $R$-squared $(<0.2)$, proving that the model is not overfit and has a good predictability. 

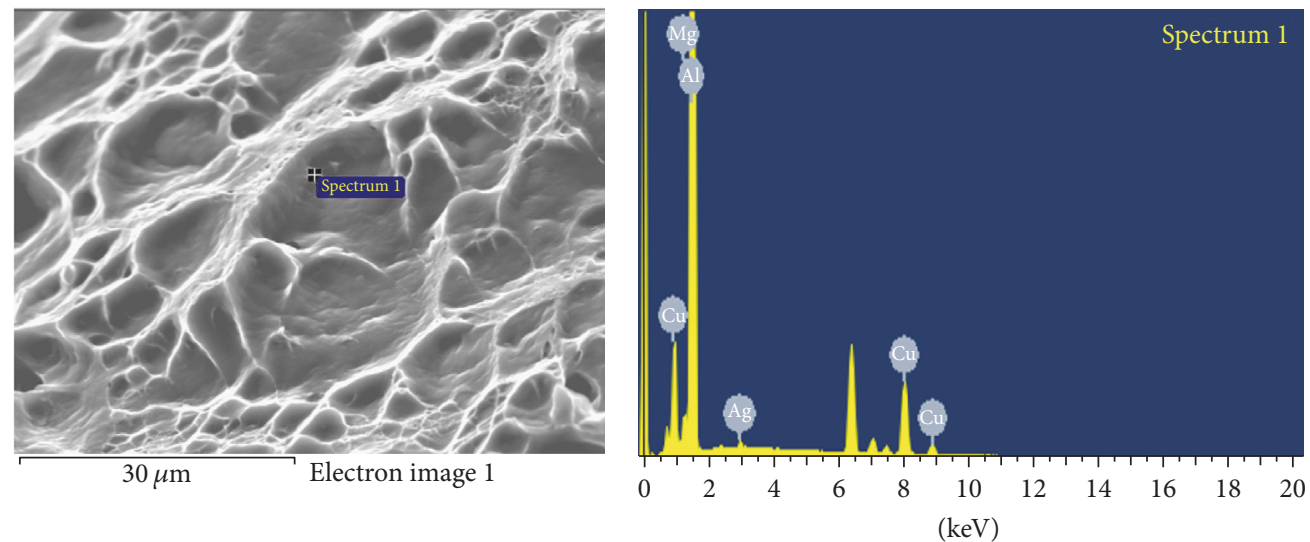

Full-scale 14049 cts. cursor: 0.000

FIGURE 8: EDS spectrum at the particle taken from fractured surfaces of Alloy 2 peak-aged condition produced by tensile testing at room temperature (Ag: 0.74 wt.\%, Mg: 0.76 wt.\%, Cu: 20.35 wt.\%, and Al: 78.15 wt.\%).

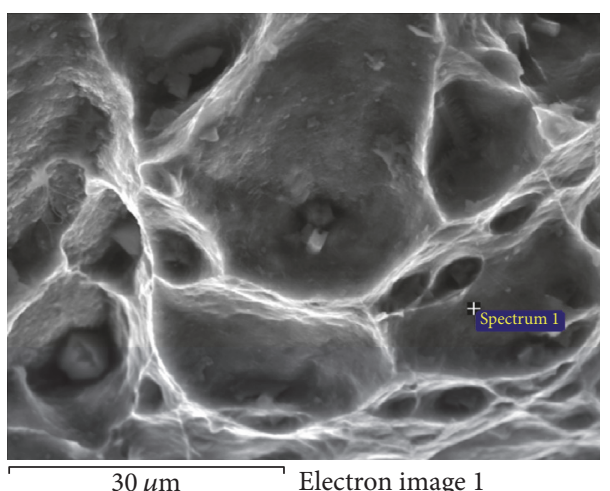

$30 \mu \mathrm{m}$

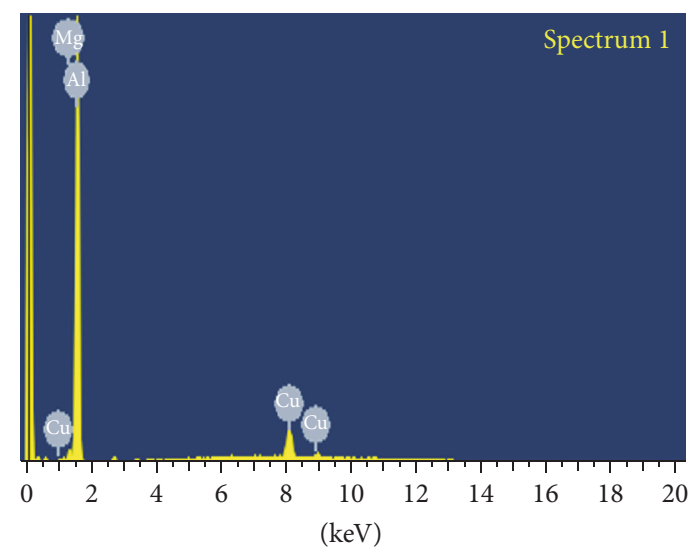

Full-scale 4631 cts. cursor: 0.000

FIGURE 9: EDS spectrum at the particle taken from fractured surfaces of Alloy 2 peak-aged condition produced by tensile testing at $250^{\circ} \mathrm{C}$ (Mg: 1.95 wt.\%, Cu: 28.96 wt.\%, and Al: 69.09 wt.\%).

TABLE 7: The DOE and experimental results for the high-temperature study.

\begin{tabular}{|c|c|c|c|c|c|c|}
\hline Time & Temp. & $\mathrm{Cu}$ & $\mathrm{Mg}$ & $\mathrm{Ag}$ & Yield strength $(\mathrm{MPa})$ & Ultimate tensile strength $(\mathrm{MPa})$ \\
\hline$A$ & $B$ & $C$ & $D$ & E & Y & $U$ \\
\hline $\begin{array}{ll}-1 \\
\end{array}$ & -1 & -1 & -1 & 1 & 190 & 219.7 \\
\hline 1 & -1 & -1 & -1 & 1 & 250 & 270.5 \\
\hline-1 & 1 & -1 & -1 & 1 & 190 & 201.0 \\
\hline 1 & 1 & -1 & -1 & 1 & 185 & 194.5 \\
\hline-1 & -1 & 1 & -1 & -1 & 315 & 353.8 \\
\hline 1 & -1 & 1 & -1 & -1 & 350 & 372.0 \\
\hline-1 & 1 & 1 & -1 & -1 & 250 & 259.5 \\
\hline 1 & 1 & 1 & -1 & -1 & 247 & 247.1 \\
\hline-1 & -1 & -1 & 1 & -1 & 250 & 310.0 \\
\hline 1 & -1 & -1 & 1 & -1 & 210 & 236.6 \\
\hline-1 & 1 & -1 & 1 & -1 & 200 & 213.8 \\
\hline 1 & 1 & -1 & 1 & -1 & 190 & 195.0 \\
\hline-1 & -1 & 1 & 1 & 1 & 295 & 320.0 \\
\hline 1 & -1 & 1 & 1 & 1 & 320 & 341.0 \\
\hline-1 & 1 & 1 & 1 & 1 & 200 & 220.0 \\
\hline 1 & 1 & 1 & 1 & 1 & 210 & 245.0 \\
\hline
\end{tabular}


TABLE 8: Analysis of variance (ANOVA) results of yield strength for the high-temperature study.

\begin{tabular}{|c|c|c|c|c|c|}
\hline Source & $\mathrm{DF}$ & Adj. SS & Adj. MS & $F$-value & $P$ value \\
\hline Model & 4 & 38548 & 9637.1 & 23.73 & 0 \\
\hline Linear & 3 & 35008 & 11669.4 & 28.74 & 0 \\
\hline$B$ & 1 & 16129 & 16129 & 39.72 & 0 \\
\hline C & 1 & 17030 & 17030.2 & 41.94 & 0 \\
\hline E & 1 & 1849 & 1849 & 4.55 & 0.056 \\
\hline 2-way interactions & 1 & 3540 & 3540.2 & 8.72 & 0.013 \\
\hline$B * C$ & 1 & 3540 & 3540.2 & 8.72 & 0.013 \\
\hline Error & 11 & 4467 & 406 & & \\
\hline Total & 15 & 43015 & & & \\
\hline
\end{tabular}

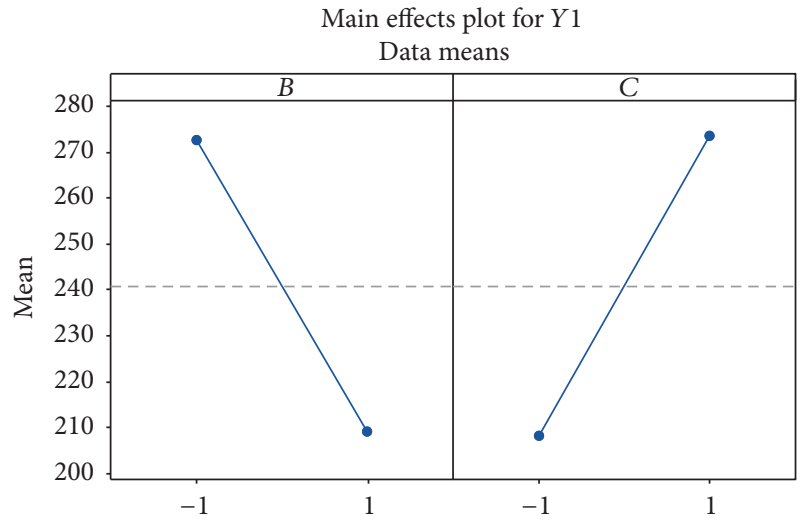

FIGURE 10: Main effect of significant factors on yield strength for the high-temperature study.

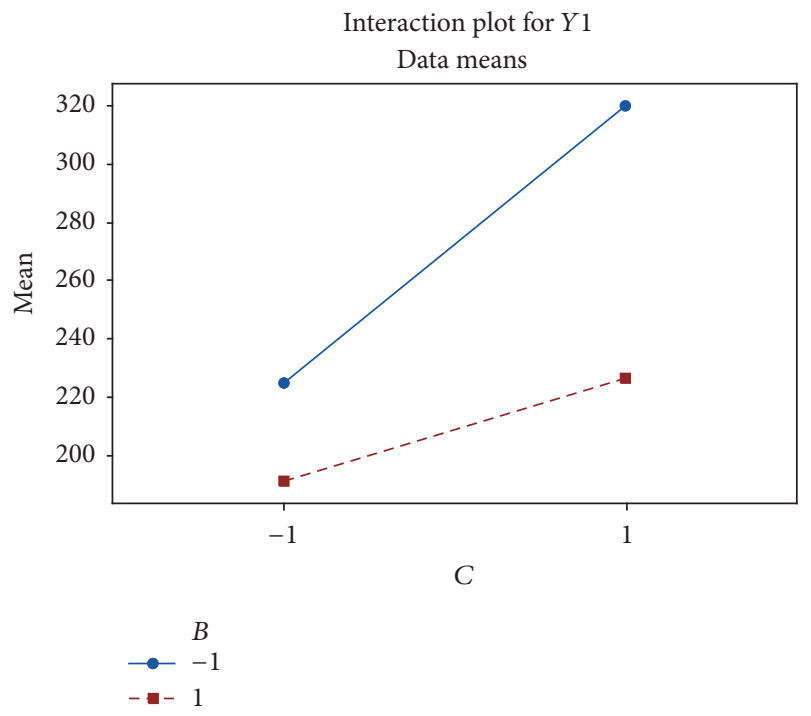

FIGURE 11: Interaction plot for yield strength for the hightemperature study.

Figures 10 and 11 show the main effect plot and interaction plot for yield strength, respectively. Figure 10 illustrates that increasing the temperature reduces the yield strength, while increasing the copper content increases the yield strength.
TABLE 9: Model summary of yield strength for the high-temperature study.

\begin{tabular}{lccc}
\hline$S$ & $R$-sq. & $R$-sq. (adj.) & $R$-sq. (pred.) \\
\hline 20.15 & $89.62 \%$ & $85.84 \%$ & $78.03 \%$ \\
\hline
\end{tabular}

In Figure 11, the interaction is visible as the two lines are not parallel. It is clear that the effect of copper content on increasing the yield strength is reduced as the temperature increases.

Equation (2) gives the regression model for yield strength:

$$
Y=-61+0.925 B+141.7 C-71.7 E-0.496 B * C \text {. }
$$

The ANOVA results for ultimate tensile strength are given in Table 10. The model has an $F$-value of 21.7 with a $P$ value of about 0.000 implying that the model is significant relative to noise. Significant terms are $B$ (temperature), $C$ (copper content), $E$ (silver content), and the interactions $A E$ and $B C$. Recall that the effect of $C$ includes the interaction $D E$ $(\mathrm{Mg}$ and $\mathrm{Ag}$ ) and the effect of $E$ includes the interaction $C D$ as given by the alias structure. Assuming that the thirdand fourth-level interactions are negligible, the effects of factor $B$ and interactions $B C$ and $A E$ are calculated with no interference from other terms. The results suggest that aging time and magnesium content do not affect the tensile strength. However, the aging time has an interactive effect with the silver content. The values of the adjusted sum of squares (Adj. SS) show that the variability in the measured ultimate tensile strength comes mainly from the testing temperature followed by the copper content. Previous work [7] reported that the tensile strength did not increase directly with increasing $\mathrm{Mg}$ content in $\mathrm{Al}-\mathrm{Cu}-\mathrm{Mg}-\mathrm{Ag}$ alloy, which agrees with the current results. On the other hand, though the aging time plays a major role in varying the hardness values, it did not impart a major effect on the tensile properties (yield and ultimate) especially for the testing temperature of $250^{\circ} \mathrm{C}$. However, at the $190^{\circ} \mathrm{C}$ testing temperature, the variation in yield and ultimate strength is present but not with a systematic trend, which could have led to the present statistical prediction of the model. It is worth noting that aging was conducted at $190^{\circ} \mathrm{C}$, for all samples; thus, for the testing temperature of $190^{\circ} \mathrm{C}$, the effect of under- and peak-aged precipitate conditions was obvious. This effect is 
TABLE 10: Analysis of variance (ANOVA) results of ultimate tensile strength for the high-temperature study.

\begin{tabular}{|c|c|c|c|c|c|}
\hline Source & $\mathrm{DF}$ & Adj. SS & Adj. MS & $F$-value & $P$ value \\
\hline Model & 6 & 48921.4 & 8153.6 & 21.65 & 0 \\
\hline Linear & 4 & 44883.8 & 11221 & 29.8 & 0 \\
\hline$A$ & 1 & 1 & 1 & 0 & 0.961 \\
\hline$B$ & 1 & 26219.7 & 26219.7 & 69.64 & 0 \\
\hline$C$ & 1 & 16725 & 16725 & 44.42 & 0 \\
\hline$E$ & 1 & 1938.2 & 1938.2 & 5.15 & 0.049 \\
\hline 2-way interactions & 2 & 4037.6 & 2018.8 & 5.36 & 0.029 \\
\hline$A * E$ & 1 & 1951.4 & 1951.4 & 5.18 & 0.049 \\
\hline$B * C$ & 1 & 2086.2 & 2086.2 & 5.54 & 0.043 \\
\hline Error & 9 & 3388.7 & 376.5 & & \\
\hline Total & 15 & 52310.2 & & & \\
\hline
\end{tabular}

TABLE 11: Model summary of ultimate tensile strength for the hightemperature study.

\begin{tabular}{lccc}
\hline$S$ & $R$-sq. & $R$-sq. (adj.) & $R$-sq. (pred.) \\
\hline 19.4043 & $93.52 \%$ & $89.20 \%$ & $79.53 \%$ \\
\hline
\end{tabular}

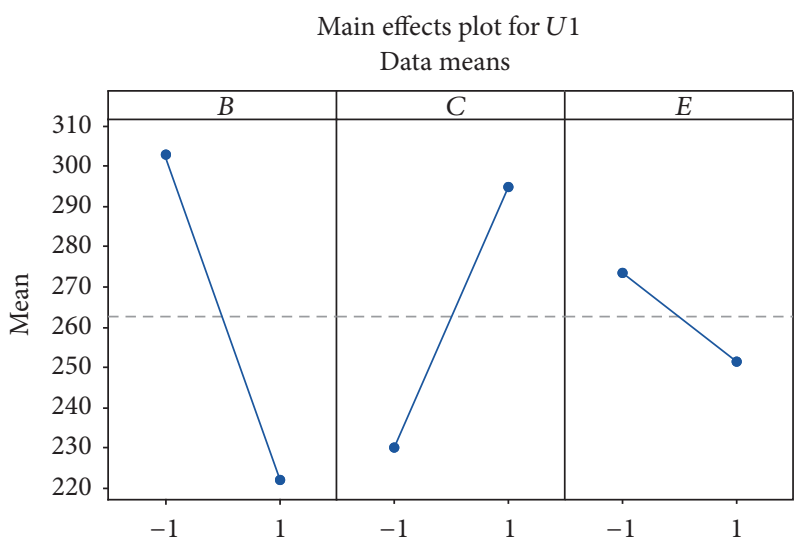

FIGURE 12: Main effect of significant factors on ultimate tensile strength for the high-temperature study.

expected to be less pronounced at higher testing temperature due to the precipitates coarsening that limits the strain hardening processes.

The model analysis summary is illustrated in Table 11. The adjusted $R$-squared equal to 0.89 implies that the model represents $89 \%$ of the variation in the data while the predicted $R$-squared was calculated as 0.79 .

Figures 12 to 14 show the main effect plot and interaction plots, respectively, for ultimate tensile strength. Figure 12 illustrates that increasing the temperature reduces the tensile strength. Increasing the copper content increases the tensile strength while increasing the silver content reduces it. In Figure 13, the interaction is visible as the two lines are not parallel. It is clear that the effect of copper content on increasing the tensile strength is reduced with increasing temperature. Figure 14 shows that although factor $A$ (aging time) is not significant by itself, it seems that increasing

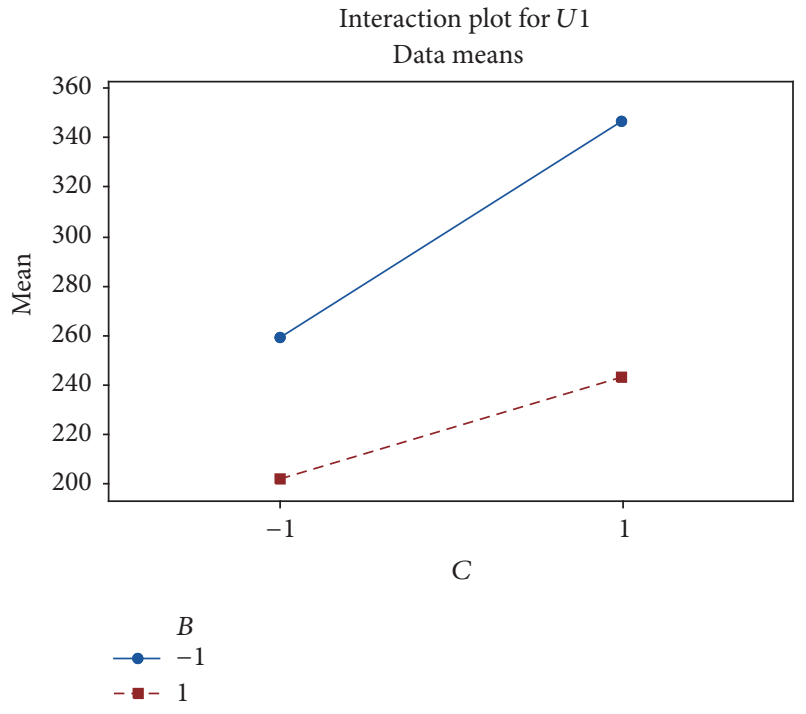

FIGURE 13: Interaction plot of copper content and temperature $B C$ for ultimate tensile strength for the high-temperature study.

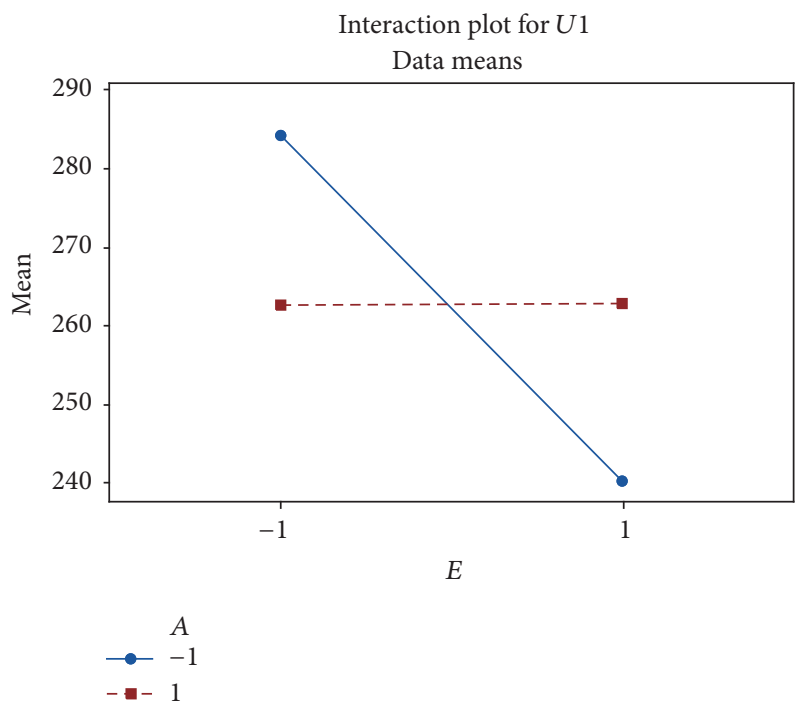

FIGURE 14: Interaction plot of silver content and time $A E$ for ultimate tensile strength for the high-temperature study. 
TABLE 12: Model predicted values versus measured values for validating alloy ( $\mathrm{Al}-3 \mathrm{Cu}-0.5 \mathrm{Mg}-0.3 \mathrm{Ag})$ for the high-temperature study.

\begin{tabular}{lcccccc}
\hline & & \multicolumn{2}{c}{ Yield strength $(\mathrm{MPa})$} & \multicolumn{3}{c}{ Ultimate tensile strength $(\mathrm{MPa})$} \\
& Measured & Predicted & Relative \% error & Measured & Predicted & Relative \% error \\
\hline Underaged $\left(190^{\circ} \mathrm{C}\right)$ & 200 & 236 & $15.3 \%$ & 239 & 248 & $3.6 \%$ \\
Peak-aged $\left(190^{\circ} \mathrm{C}\right)$ & 240 & 236 & $-1.7 \%$ & 245 & 292 & $16.1 \%$ \\
Underaged $\left(250^{\circ} \mathrm{C}\right)$ & 165 & 202 & $18.3 \%$ & 173 & 190 & $9 \%$ \\
Peak-aged $\left(250^{\circ} \mathrm{C}\right)$ & 160 & 202 & $20.8 \%$ & 173 & 234 & $26 \%$ \\
\hline
\end{tabular}

the time at high silver content reduces the tensile strength significantly.

Equation (3) gives the regression model for tensile strength:

$$
\begin{aligned}
U 1= & 128+0.173 B+116.1 C-73.4 E+73.6 A * E \\
& -0.381 B * C .
\end{aligned}
$$

3.3.1. Validation. To validate the model, an extra alloy was prepared and tested under the same testing conditions as the main designed alloys. The validating alloy had $\mathrm{Cu}$ (3 wt.\%), $\mathrm{Mg}$ (0.5 wt.\%), and $\mathrm{Ag}$ (0.3 wt.\%). The alloy was tested under two temperatures $\left(190\right.$ and $\left.250^{\circ} \mathrm{C}\right)$ and under two conditions of aging (underaged and peak-aged). The measured yield strength and tensile strength of the alloy are given in Table 12 in comparison to model predicted values. Note that the value of factor $A$ (time) is substituted in the equations as -1 for the underaged condition and +1 for the peak-aged condition, while the other factors are substituted by their actual values.

Paired $t$-test was used to estimate the significance of the difference between the measured and the predicted values. The test proved no significant difference with $P$ value $=0.081$ for the yield strength and 0.074 for ultimate tensile strength. However, as the model was built on a fractional factorial design, it might lack some significant interactions that were omitted in the current study. This may be the reason for some large errors (above 20\%) shown in Table 12. A more compressive model should be considered as an extension to this study.

\section{Conclusions}

Four alloys with different compositions of $\mathrm{Al}-\mathrm{Cu}-\mathrm{Mg}-\mathrm{Ag}$ were cast. The alloys were homogenized and hot-rolled. Tensile samples were cut from the rolled sheet. These samples were solution-treated and then aged at $190^{\circ} \mathrm{C}$ for different aging times comprising underaged and peak-aged conditions. Tensile testing was conducted at room and high temperatures. Changing weight percentages of alloying elements had significant effects on the mechanical properties. The sensitivity of mechanical properties for temperatures was measured through calculating the negative slopes of the yield and ultimate tensile strength variation with temperature.

A mathematical model for the variation of yield strength and ultimate tensile strength was built to relate them with alloying elements content, aging time, and tensile testing temperatures. Both models represent more than $80 \%$ of the variation in the data, which represents the reliability of the models. Copper content was most significant for increasing the yield strength and ultimate tensile strength. As expected, increasing temperature reduces the values of YS and UTS.

The promising mechanical properties and the lower sensitivity to high temperatures of $\mathrm{Al}-\mathrm{Cu}-\mathrm{Mg}-\mathrm{Ag}$ make them a potential replacement for A2618 and other aluminum alloys used in high-temperature applications such as supersonic aviation and automobile industry.

\section{Conflicts of Interest}

The authors declare that they have no conflicts of interest.

\section{Acknowledgments}

The authors are thankful to the financial and logistic support of King Abdullah Institute for Nanotechnology and the Deanship of Scientific Research, King Saud University, Riyadh, Saudi Arabia.

\section{References}

[1] M. Gazizov and R. Kaibyshev, "Low-cyclic fatigue behaviour of an Al-Cu-Mg-Ag alloy under T6 and T840 conditions," Materials Science and Technology (United Kingdom), pp. 1-11, 2016.

[2] P. Lequeu, "Advances in aerospace aluminum," Advanced Materials \& Processes, pp. 47-49, 2008.

[3] M. Macar, Investigation of Dynamics of Behavior of Aluminum Alloy Armor Materials [Ph.D. thesis], Middle East technical University, 2014.

[4] J. C. Williams and E. A. Starke Jr., "Progress in structural materials for aerospace systems," Acta Materialia, vol. 51, no. 19, pp. 5775-5799, 2003.

[5] J. S. Robinson, R. L. Cudd, and J. T. Evans, "Creep resistant aluminium alloys and their applications," Materials Science and Technology, vol. 19, no. 2, pp. 143-155, 2003.

[6] C. L. Lach and M. S. Domack, "Characterization of Al-Cu-MgAg Alloy RX226-T8 Plate,” NASA/TM-2003-212639, 2003.

[7] S. Bai, P. Ying, Z. Liu, J. Wang, and J. Li, "Quantitative transmission electron microscopy and atom probe tomography study of Ag-dependent precipitation of $\Omega$ phase in Al-Cu-Mg alloys," Materials Science and Engineering: A, vol. 687, pp. 8-16, 2017.

[8] S. Bai, X. Zhou, Z. Liu, P. Xia, M. Liu, and S. Zeng, "Effects of Ag variations on the microstructures and mechanical properties of Al-Cu-Mg alloys at elevated temperatures," Materials Science and Engineering A, vol. 611, pp. 69-76, 2014.

[9] D. Bakavos, P. B. Prangnell, B. Bes, and F. Eberl, "The effect of silver on microstructural evolution in two $2 \mathrm{xxx}$ series Al-alloys 
with a high $\mathrm{Cu}: \mathrm{Mg}$ ratio during ageing to a T8 temper," Materials Science and Engineering A, vol. 491, no. 1-2, pp. 214-223, 2008.

[10] R. N. Lumley and I. J. Polmear, "The effect of long term creep exposure on the microstructure and properties of an underaged Al-Cu-Mg-Ag alloy,' Scripta Materialia, vol. 50, no. 9, pp. 12271231, 2004.

[11] B. M. Gable, G. J. Shiflet, and J. Starke, "Alloy development for the enhanced stability of $\Omega$ precipitates in Al-Cu-Mg-Ag alloys," Metallurgical and Materials Transactions A: Physical Metallurgy and Materials Science, vol. 37, no. 4, pp. 1091-1105, 2006.

[12] D. H. Xiao, J. N. Wang, D. Y. Ding, and H. L. Yang, "Effect of rare earth Ce addition on the microstructure and mechanical properties of an Al-Cu-Mg-Ag alloy," Journal of Alloys and Compounds, vol. 352, no. 1-2, pp. 84-88, 2003.

[13] S. Bai, Z. Liu, Y. Li, Y. Hou, and X. Chen, "Microstructures and fatigue fracture behavior of an $\mathrm{Al}-\mathrm{Cu}-\mathrm{Mg}-\mathrm{Ag}$ alloy with addition of rare earth Er," Materials Science and Engineering A, vol. 527, no. 7-8, pp. 1806-1814, 2010.

[14] A. Cho and B. Bes, "Damage tolerance capability of an Al-CuMg-Ag alloy(2139)," Materials Science Forum, vol. 519-521, no. 1, pp. 603-608, 2006.

[15] M. Song, K.-H. Chen, and L.-P. Huang, "Effects of Ag addition on mechanical properties and microstructures of $\mathrm{Al}-8 \mathrm{Cu}-$ $0.5 \mathrm{Mg}$ alloy," Transactions of Nonferrous Metals Society of China (English Edition), vol. 16, no. 4, pp. 766-771, 2006.

[16] Q. K. Xia, Z. Y. Liu, and Y. T. Li, "Microstructure and properties of $\mathrm{Al}-\mathrm{Cu}-\mathrm{Mg}-\mathrm{Ag}$ alloy exposed at $200^{\circ} \mathrm{C}$ with and without stress," Transactions of Nonferrous Metals Society of China (English Edition), vol. 18, no. 4, pp. 789-794, 2008.

[17] X. Y. Liu, Q. L. Pan, X. L. Zhang et al., "Creep behavior and microstructural evolution of deformed $\mathrm{Al}-\mathrm{Cu}-\mathrm{Mg}-\mathrm{Ag}$ heat resistant alloy," Materials Science and Engineering A, vol. 599, pp. 160-165, 2014.

[18] R. N. Lumley, A. J. Morton, and I. J. Polmear, "Enhanced creep performance in an $\mathrm{Al}-\mathrm{Cu}-\mathrm{Mg}-\mathrm{Ag}$ alloy through underageing," Acta Materialia, vol. 50, no. 14, pp. 3597-3608, 2002.

[19] A. M. Al-Obaisi, E. A. El-Danaf, A. E. Ragab, and M. S. Soliman, "Precipitation Hardening and Statistical Modeling of the Aging Parameters and Alloy Compositions in Al-Cu-Mg-Ag Alloys," Journal of Materials Engineering and Performance, pp. 1-13, 2016.

[20] J. C. Lourenço, M. I. S. T. Faria, A. Robin, L. P. Prisco, and M. C. Puccini, "Influence of process parameters on localized corrosion of AA7075 alloy during the production of aeronautic components," Materials and Corrosion, vol. 66, no. 12, pp. 14981503, 2015.

[21] T. A. El-Taweel and S. Haridy, "An application of fractional factorial design in wire electrochemical turning process," International Journal of Advanced Manufacturing Technology, vol. 75, no. 5-8, pp. 1207-1218, 2014.

[22] E. M. Salleh, H. Zuhailawati, S. Ramakrishnan, and M. A.H. Gepreel, "A statistical prediction of density and hardness of biodegradable mechanically alloyed $\mathrm{Mg}-\mathrm{Zn}$ alloy using fractional factorial design," Journal of Alloys and Compounds, vol. 644, pp. 476-484, 2015.

[23] I. J. Polmear and M. J. Couper, "Design and development of an experimental wrought aluminum alloy for use at elevated temperatures," Metallurgical Transactions A, vol. 19, no. 4, pp. 1027-1035, 1988.

[24] K. M. Knowles and W. M. Stobbs, "The structure of 111 age-hardening precipitates in $\mathrm{Al}-\mathrm{Cu}-\mathrm{Mg}-\mathrm{Ag}$ alloys," Acta Crystallographica Section B, vol. 44, no. 3, pp. 207-227, 1988.
[25] B. C. Muddle and I. J. Polmear, “The precipitate $\Omega$ phase in AlCu-Mg-Ag alloys," Acta Metallurgica, vol. 37, no. 3, pp. 777-789, 1989.

[26] A. Garg, Y. C. Chang, and J. M. Howe, "Precipitation of the $\Omega$ phase in an Al-4.0Cu- $0.5 \mathrm{Mg}$ alloy," Scripta Metallurgica et Materiala, vol. 24, no. 4, pp. 677-680, 1990.

[27] M. Grujicic, G. Arakere, C.-F. Yen, and B. A. Cheeseman, "Computational investigation of hardness evolution during friction-stir welding of AA5083 and AA2139 aluminum alloys," Journal of Materials Engineering and Performance, vol. 20, no. 7, pp. 1097-1108, 2011. 

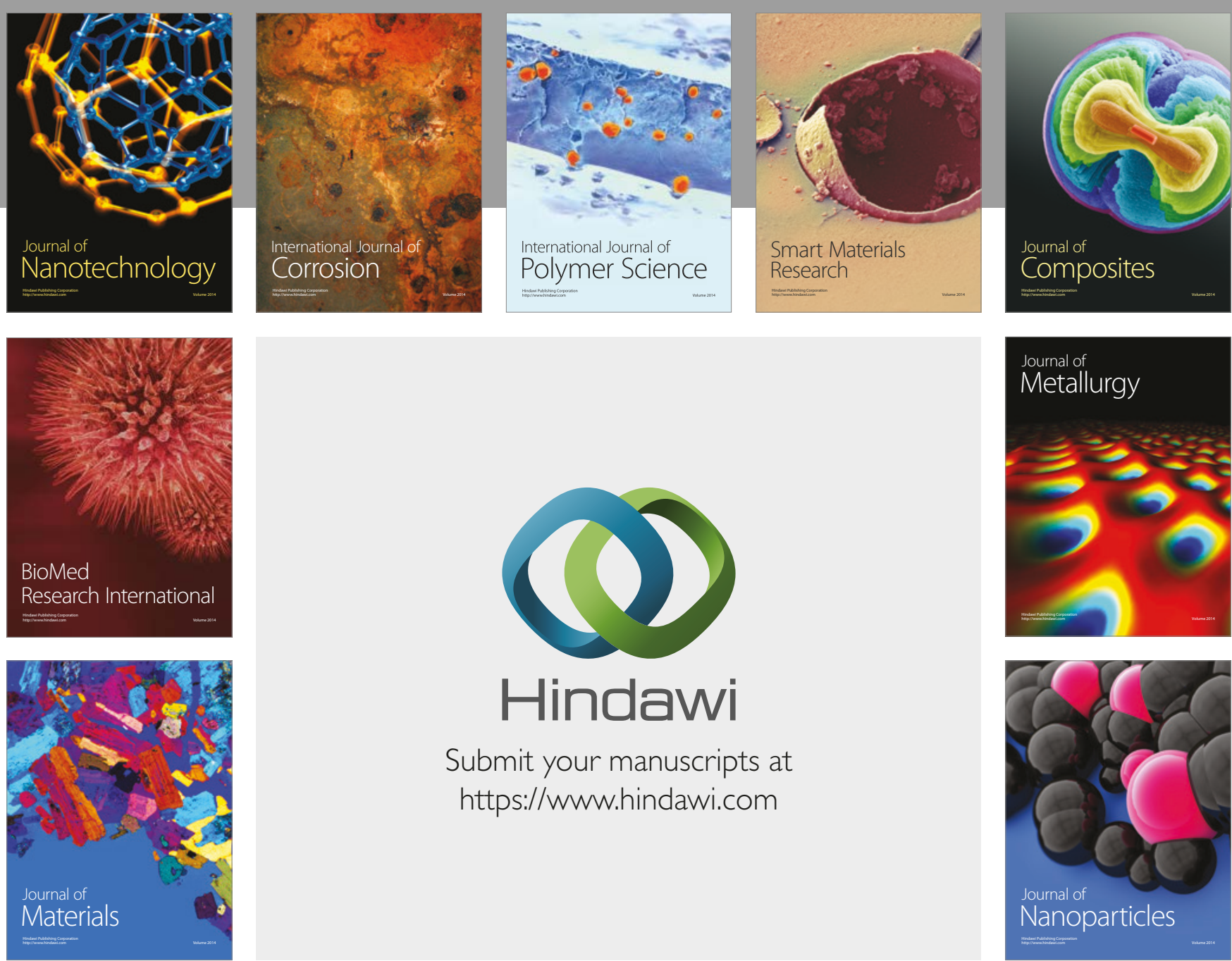

\section{Hindawi}

Submit your manuscripts at

https://www.hindawi.com
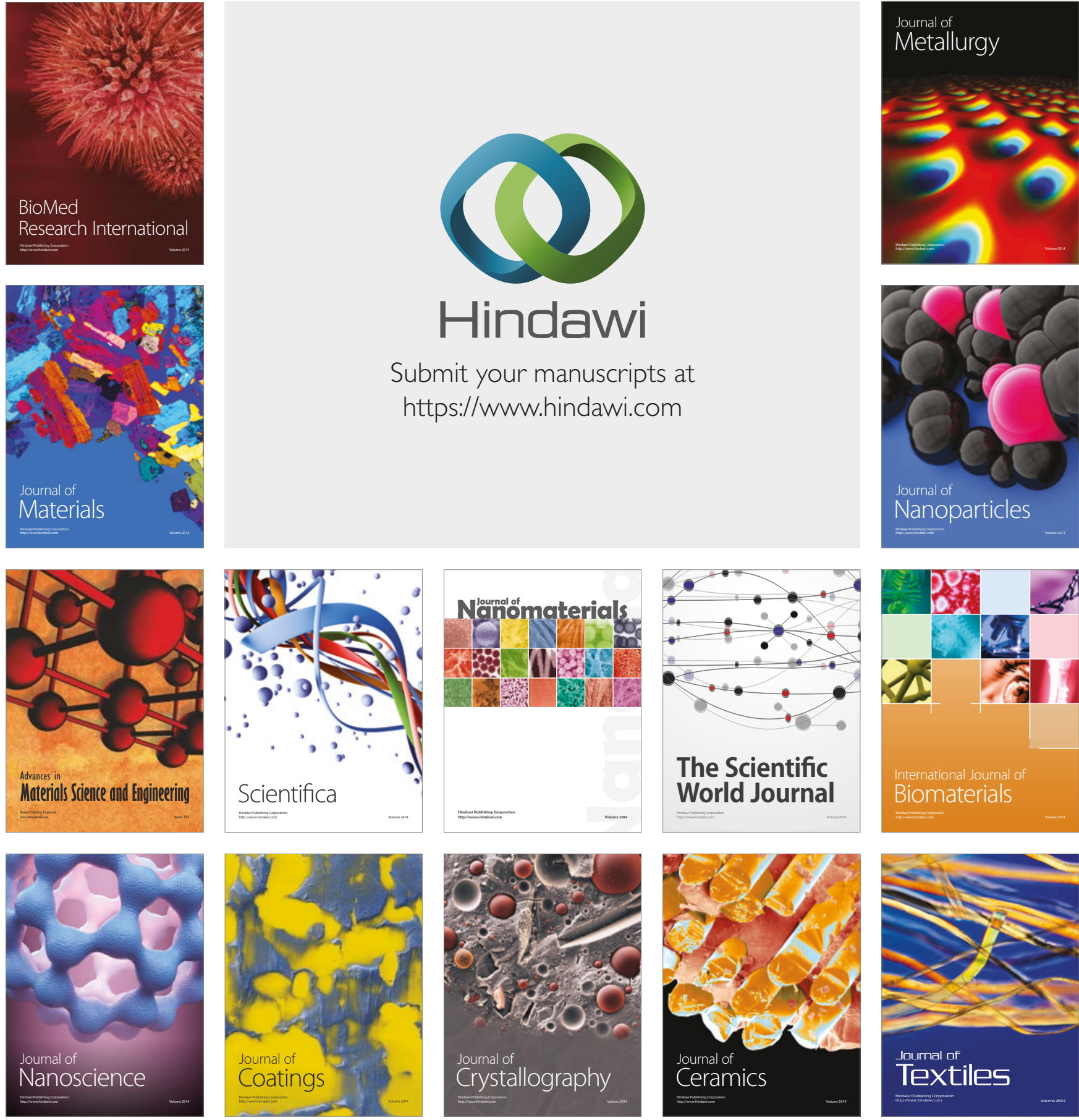

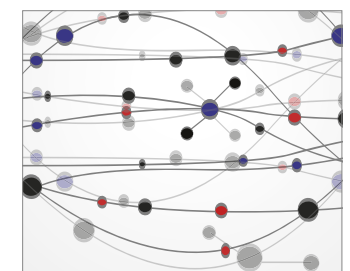

The Scientific World Journal
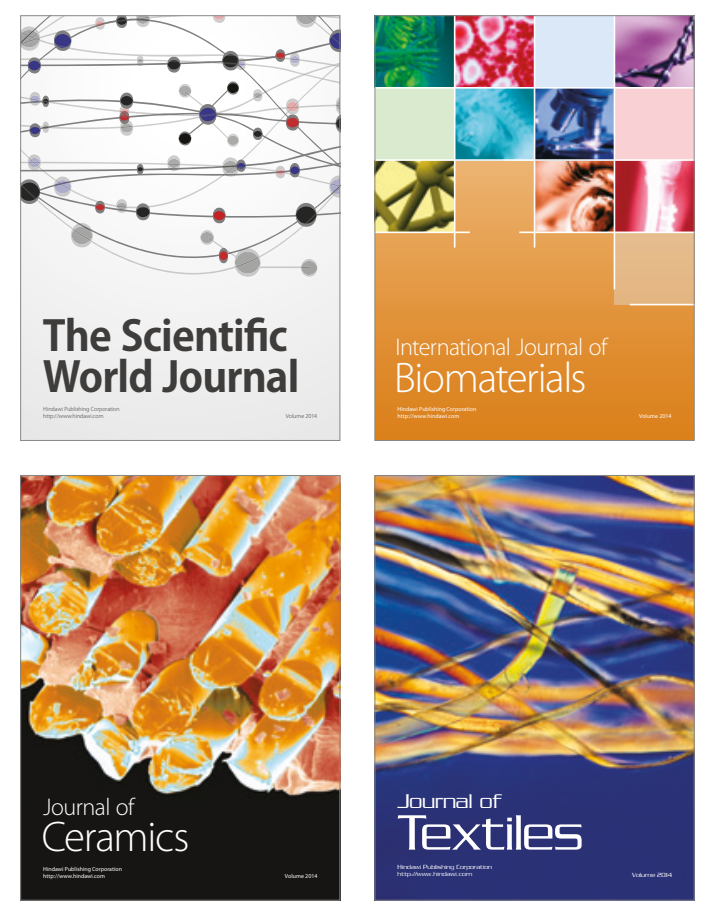